\title{
Iron chelation monotherapy in transfusion-dependent beta-thalassemia major patients: a comparative study of deferasirox and deferoxamine
}

\author{
Mohamed Abdel Malik Hassan ${ }^{1}$, Omar Atef Tolba ${ }^{2}$
}

${ }^{1}$ MD, Lecturer of Pediatrics, Department of Pediatrics, Al-Azhar University, Egypt

${ }^{2}$ Ph.D., Consultant of Pediatrics, Cairo University Children's Hospital, Department of Pediatrics, Cairo University, Egypt

\section{Type of article: Original}

\begin{abstract}
Introduction: Iron overload is the primary cause of mortality and morbidity in thalassemia major (TM) despite advances in chelation therapy. The aim of this study was to compare the effectiveness and safety of deferasirox (DFX) and deferoxamine (DFO) as iron-chelating agents in patients with transfusion-dependent $\beta$-thalassemia major.

Methods: This prospective randomized study included 60 patients with transfusion-dependent $\beta$-TM during the period from September 2014 to September 2015. Their ages were $\geq 6$ years, and they had serum ferritin above $1500 \mu \mathrm{g} / \mathrm{L}$ and were on irregular DFO therapy. Patients had regular packed red cell transfusion in a dose of 10 $\mathrm{mL} / \mathrm{kg} / \mathrm{session}$. They were randomized to receive DFX (single oral daily dose of $20-40 \mathrm{mg} / \mathrm{kg} / \mathrm{day}$ ) or DFO (20$50 \mathrm{mg} / \mathrm{kg}$ /day via subcutaneous infusion over 8-10 hours, 5 days a week). Iron overload was determined by serum ferritin level. The primary endpoint was decrease of serum ferritin level below $1500 \mu \mathrm{g} / \mathrm{L}$. The secondary endpoint was drug safety.

Results: Both drugs significantly reduced serum ferritin $(\mathrm{p}<0.001)$. At the end of follow-up, there were no significant differences between the two groups in serum ferritin levels $(p=0.673)$ and in percent reduction of ferritin $(p=0.315)$. There were no significant differences between the two groups in the total amount of blood transfusion $(p=0.166)$ and average iron intake $(p=0.227)$. There were no mortalities or any serious adverse effects, neutropenia, arthropathy, or pulmonary toxicity. Gastrointestinal upset and skin rash occurred more frequently with DFX than with DFO ( $\mathrm{p}=0.254$ and 0.095 , respectively).

Conclusion: With appropriate dosing and compliance with drugs, both DFX and DFO are generally well tolerated, safe, and effective in reducing serum ferritin levels in iron-overloaded, regularly-transfused thalassemia major patients. Therefore, oral DFX is recommended for more convenience and adherence to the treatment regimen.
\end{abstract}

Keywords: iron chelators, iron overload, thalassemia, efficacy, safety

\section{Introduction}

Beta-thalassemia major ( $\beta$-TM) represents a major public health problem in Egypt (1). Patients who require regular blood transfusions accumulate iron at a rate of approximately $0.5 \mathrm{mg} / \mathrm{kg} /$ day (2). This excess iron is deposited in body organs, including the heart, liver, and endocrine glands, and it can cause damage to these organs (3). The iron loading depends on the volume of blood transfused and the amount of iron absorbed from the gut (4). The increased absorption of gastrointestinal iron is mediated by the down-regulation of hepcidin and up-regulation of ferroportin (5). Iron chelation therapy remains one of the main objectives of clinical management of the patients affected by TM (6). Morbidity and mortality are linked closely to the adequacy of chelation. Recent evidence has shown that TM patients can experience improved survival rates and enhanced quality of life by normalizing the iron concentrations in their bodies. Such normalization also can prevent new morbidities and may even reverse specific complications

\section{Corresponding author:}

Dr. Omar Atef Tolba, Cairo University Children's Hospital, Department of Pediatrics, Cairo University, Egypt.

Tel: +201222101717,+20233025539, Fax:+20233025539, Email: omartolba80@yahoo.com

Received: February 06, 2016, Accepted: April 06, 2016, Published: May 2016

iThenticate screening: April 06, 2016, English editing: April 12, 2016, Quality control: May 02, 2016

(C) 2016 The Authors. This is an open access article under the terms of the Creative Commons Attribution-NonCommercialNoDerivs License, which permits use and distribution in any medium, provided the original work is properly cited, the use is non-commercial and no modifications or adaptations are made. 
that may have occurred (7). Different clinical parameters are used to assess body iron burden and response to therapy with serum ferritin levels as the laboratory parameter most often used. In general, sustained ferritin levels above $2500 \mu \mathrm{g} / \mathrm{L}$ are associated with organ toxicity and death (8). Ferritin is an acute phase reactant; its serum level may be disproportionately greater than the degree of iron loading in infections, inflammatory states, liver dysfunction, and malignancies. Conversely, it is low in the presence of vitamin C deficiency. Despite its limitations, serum ferritin remains an easy, economic, and widely used indicator of chronic iron load (7). It has been shown to be more convenient than liver iron concentration by either liver biopsy, superconducting quantum interference device, or magnetic resonance imaging (9-11). Worldwide, the available chelators are deferoxamine (DFO), deferasirox (DFX) and deferiprone (DFP) (12). DFO was the first iron chelator introduced into clinical practice. Despite its effectiveness, the use of DFO is associated with significant challenges that can lead to noncompliance (13). In large randomized studies on TM, DFX has been shown to have an efficacy similar to DFO with regard to the reduction in liver iron concentration and serum ferritin levels $(9,14)$. Nevertheless, some patients fail to respond adequately to monotherapy with any of these agents (15). Comparative effectiveness trials may help to determine the ideal strategy for treating various scenarios of organ-specific iron loading. Consequently, the purpose of this study was to compare the efficacy and safety of deferasirox and deferoxamine as iron-chelating agents in patients with transfusiondependent $\beta$-thalassemia major.

\section{Material and Methods \\ 2.1. Study design}

This prospective, randomized, phase 3 study was conducted at the out-patient pediatric hematology clinic of AlHussein University Hospital, Al-Azhar University, Cairo, Egypt, during the period from September 2014 to September 2015. The study was approved by the local Ethics Committee. Informed parental consent was obtained prior to their children being enrolled in the study.

\subsection{Study population}

The study included 60 patients with transfusion-dependent $\beta$-TM. The patients' ages were $\geq 6$ years, and they had serum ferritin levels greater than $1500 \mu \mathrm{g} / \mathrm{L}$ and were on irregular subcutaneous DFO chelation therapy. We excluded patients with serum creatinine above the upper age-related normal range, significant proteinuria (urinary protein/creatinine ratio $>1.0$ in a non-first-void urine sample at baseline), elevated alanine aminotransferase (ALT) more than three-fold of the upper limit of normal, gastrointestinal diseases, clinically relevant auditory and/or ocular toxicity related to iron chelation therapy, cardiac disease, and/or serious adverse events with DFO or DFX, and absolute neutrophilic count $<1500 / \mathrm{mm}^{3}$ or platelet count $<100,000 / \mathrm{mm}^{3}$. All patients were maintained on regular packed red cell transfusion at a dose of $10 \mathrm{~mL} / \mathrm{kg} / \mathrm{session}$. The frequency of transfusion sessions was individualized for each patient according to the patient's clinical condition; the time between sessions was 2-6 weeks. Following a 7-day washout phase, the patients were randomized in a 1:1 ratio based on permuted blocks to receive deferasirox (DFX) or deferoxamine (DFO) for one year. DFX was administered orally as a single daily dose of $20-40 \mathrm{mg} / \mathrm{kg} / \mathrm{day}$ on an empty stomach after dissolution in water, apple juice, or orange juice to assure adequate bioavailability (1618). The starting dose of DFX was individualized based on the frequency of blood transfusions (14). DFO was administered at $20-50 \mathrm{mg} / \mathrm{kg} /$ day via subcutaneous infusion over $8-10$ hours, five days per week.

\subsection{Methods}

Initially, comprehensive histories were taken for all cases, including age, gender, duration and frequency of blood transfusions, and chelation therapy (type, duration and compliance with the treatment regimen). Thorough physical and clinical examinations were performed. Baseline laboratory data were recorded, including a complete blood count; levels of alanine aminotransferase (ALT), aspartate aminotransferase (AST), blood urea and serum creatinine; hepatitis B surface antigen, and hepatitis $\mathrm{C}$ antibody. In addition, audiometry and ocular examinations were done. Iron overload as determined by serum ferritin level has been established as an effective method of measuring iron overload, and it is more convenient than liver iron concentration by either liver biopsy, superconducting quantum interference device, or magnetic resonance imaging (9-11).

\subsection{Assessment}

The efficacy of chelation was assessed by change in serum ferritin from baseline and after 12 months of therapy. Safety was evaluated by clinical and laboratory monitoring of adverse effects at each transfusion visit, including complete blood count, serum transaminases, serum creatinine, blood urea, and urinary protein excretion. History of gastrointestinal disorders (anorexia, nausea, vomiting, upper abdominal pain, and diarrhea), local skin reactions (hardness, swelling, redness, and soreness), and rash or other symptoms were checked. Repeat audiometry and 
ocular examinations were performed at the end of the study. Study medications were dispensed during regular study visits with strict follow-up. During the study, we kept records of all dosages administered, all study medications that were dispensed and returned, and intervals between visits to determine compliance with the treatment. The patients' parents were instructed to contact the investigator if the patients were unable to take the study drug as prescribed. The transfusional iron intake during the study period was calculated according to Porter (19). DFX dose adjustment was based on continuous assessment of safety markers including changes in serum creatinine, urinary protein: urinary creatinine ratio, liver function tests, development of skin rash, auditory and ocular disturbances, cytopenias and hypersensitivity reactions (14). The risk of the adverse effects associated with DFO was minimized by maintaining the ratio of the mean daily dose of deferoxamine $(\mathrm{mg} / \mathrm{kg})$ to the serum ferritin level $(\mu \mathrm{g} / \mathrm{L})$ at less than 0.025 (20), calculated for each patient every six months.

\subsection{Endpoints}

The primary endpoint was the decrease in the serum ferritin level to less than $1500 \mu \mathrm{g} / \mathrm{L}$. Secondary endpoints were the safety of the drugs that were used.

\subsection{Statistical analysis}

Statistical analysis was done using IBM(C) SPSS $\odot$ Statistics, version 22 (IBMC Corp., Armonk, NY, USA). Numerical data were expressed as mean and standard deviation or median and range, as appropriate. Qualitative data were expressed as frequency and percentage. Chi square test and Fisher's exact test were used to examine the relation between qualitative variables. For quantitative data, the two groups were compared using the independent samples t-test or Mann-Whitney test. All tests were two-tailed. A p-value $<0.05$ was considered significant.

\section{Results}

Table 1 demonstrates the demographic and baseline clinical characteristics of the studied groups, showing comparable characteristics between the two groups, including age, weight, gender distribution, years of blood transfusion, baseline hematologic parameters, and renal functions; and significantly higher rates of splenectomy ( $<<$ $0.001)$, hepatitis $C(p=0.005)$, and serum levels of Alanine transaminase (ALT) $(p<0.001)$ and Aspartate transaminase (AST) $(\mathrm{p}=0.003)$ in the DFO group compared to the DFX group.

Table 1. Demographic and baseline clinical characteristics of the studied groups

\begin{tabular}{|l|l|l|l|}
\hline Variables & DFX Group $(\mathrm{n}=30)$ & DFO Group $(\mathrm{n}=30)$ & $p$-value \\
\hline Age (years) & $8.9 \pm 2.2(8-13)$ & $9.7 \pm 1.9(10-13)$ & 0.123 \\
\hline Gender (Male/Female) & $9 / 21$ & $10 / 20$ & 0.781 \\
\hline Parental consanguinity & $5(20)$ & $12(48)$ & 0.072 \\
\hline Weight $(\mathrm{kg})$ & $23.4 \pm 6.1$ & $25.0 \pm 6.4$ & 0.307 \\
\hline Splenectomy & $4(13.3)$ & $17(56.7)$ & $<0.001$ \\
\hline Hepatitis status & $2(6.7)$ & $11(36.7)$ & 0.005 \\
\hline & 0 & 0 & - \\
\hline Time since start of blood transfusion (years) & $3.7 \pm 1.1$ & $3.8 \pm 1.5$ & 0.945 \\
\hline Hemoglobin concentration $(\mathrm{gm} / \mathrm{dL})$ & $8.5 \pm 1.2$ & $7.9 \pm 2.4$ & 0.467 \\
\hline Absolute neutrophilic count $\left(/ \mathrm{mm}^{3}\right)$ & $2150 \pm 410$ & $2340 \pm 526$ & 0.124 \\
\hline Platelet count $\left(\mathrm{x} 10^{3} / \mathrm{mm}^{3}\right)$ & $356 \pm 43$ & $372 \pm 56$ & 0.220 \\
\hline ALT $(\mathrm{U} / \mathrm{L})$ & $28.2 \pm 16.3$ & $46.1 \pm 23.7$ & $<0.001$ \\
\hline AST $(\mathrm{U} / \mathrm{L})$ & $31.0 \pm 13.8$ & $51.5 \pm 32.9$ & 0.003 \\
\hline Serum creatinine $(\mathrm{mg} / \mathrm{dL})$ & $0.77 \pm 0.21$ & $0.81 \pm 0.10$ & 0.331 \\
\hline Blood urea $(\mathrm{mg} / \mathrm{dL})$ & $29.6 \pm 10.3$ & $31.1 \pm 6.8$ & 0.508 \\
\hline Serum ferritin $(\mu \mathrm{g} / \mathrm{L})$ & $3216(2100-5862)$ & $2773(1980-4884)$ & 0.255 \\
\hline
\end{tabular}

Data are expressed as mean \pm standard deviation (range), median (range), ratio and frequency (percentage).

In the DFX group, the mean daily dose over 1-year treatment was $28.7 \pm 5.6 \mathrm{mg} / \mathrm{kg} / \mathrm{day}$, while, in the DFO group, the mean dose was $29.6 \pm 6.6 \mathrm{mg} / \mathrm{kg} / \mathrm{day}$. The maximum doses of DFX and DFO used during the study period were $39.4 \mathrm{mg} / \mathrm{kg} /$ day and $43.5 \mathrm{mg} / \mathrm{kg} / \mathrm{day}$, respectively. There was no significant difference between the two groups in the total amount of blood transfusion $(\mathrm{p}=0.166)$ and average iron intake $(\mathrm{p}=0.227)$. After one year of treatment, significant reduction of serum ferritin levels was observed in the two groups $(p<0.001)$. The mean serum ferritin levels at the end of follow-up were comparable between the two groups $(\mathrm{p}=0.673)$. The median percent reduction 
was $47.2 \%$ (range: $-1.2-69.1 \%$ ) with DFX compared to $50.3 \%$ (range: $-7.7-61.2 \%)$ with DFO $(\mathrm{p}=0.315)$. The proportion of patients with post-treatment serum ferritin level $<1500 \mu \mathrm{g} / \mathrm{L}$ was 17 cases with DFX $(56.7 \%)$ compared to 19 cases $(63.3 \%)$ with DFO $(p=0.598)$. Post-treatment levels of ALT and AST were significantly higher in the DFO group ( $\mathrm{p}=0.022, \mathrm{p}=0.020$, respectively), and the high levels were associated with HCV positivity. Blood urea was significantly higher in the DFX group $(\mathrm{p}<0.001)$, however the levels were within the clinically accepted range. Serum creatinine, absolute neutrophilic and platelet counts showed a non-significant difference between the two groups (Table 2). Regarding drug-related adverse events, no cases of neutropenia, arthropathy, pulmonary toxicity, or mortalities occurred during the study. Other adverse effects of DFO as irritation and swelling at the injection site, and allergic reactions were minor, and did not lead to discontinuation of treatment. No audiological or ophthalmological toxicities were recorded. DFX related-gastrointestinal disturbances also were minor and caused no discontinuation of treatment. Throughout the study, all patients were compliant with the prescribed doses, and no discontinuation of drugs or drop-out of follow-up occurred.

Table 2. Treatment and post-treatment characteristics of the two studied groups

\begin{tabular}{|l|l|l|l|}
\hline Variable & DFX Group $(\mathrm{n}=30)$ & DFO Group $(\mathrm{n}=30)$ & $p$-value \\
\hline Mean daily dose of the drug $(\mathrm{mg} / \mathrm{kg})$ & $28.7 \pm 5.6$ & $29.6 \pm 6.6$ & - \\
\hline Total volume of blood transfusion $(\mathrm{ml} / \mathrm{kg} /$ year $)$ & $160.5 \pm 51.1$ & $142.4 \pm 48.9$ & 0.166 \\
\hline Mean transfusional iron intake $(\mathrm{mg} / \mathrm{kg} / \mathrm{day})$ & $0.30 \pm 0.1$ & $0.27 \pm 0.09$ & 0.227 \\
\hline Serum ferritin at the end of follow up $(\mu \mathrm{g} / \mathrm{L})$ & $1398(980-4842)$ & $1375(998-4650)$ & 0.673 \\
\hline Percent reduction of serum ferritin & $47.2(-1.2-69.1)$ & $50.3(-7.7-61.2)$ & 0.315 \\
\hline Post-treatment serum ferritin $<1500 \mu \mathrm{g} / \mathrm{L}$ & $17(56.7)$ & $19(63.3)$ & 0.598 \\
\hline ALT $(\mathrm{U} / \mathrm{L})$ & $35.0 \pm 25.6$ & $54.5 \pm 32.4$ & 0.022 \\
\hline AST $(\mathrm{U} / \mathrm{L})$ & $25.9 \pm 18.9$ & $42.2 \pm 27.8$ & 0.020 \\
\hline Serum creatinine $(\mathrm{mg} / \mathrm{dL})$ & $0.60 \pm 0.18$ & $0.53 \pm 0.2$ & 0.148 \\
\hline Blood urea $(\mathrm{mg} / \mathrm{dL})$ & $35.2 \pm 6.5$ & $28.1 \pm 5.7$ & $<0.001$ \\
\hline Absolute neutrophilic count $\left(/ \mathrm{mm}^{3}\right)$ & $1980 \pm 605$ & $2098 \pm 554$ & 0.434 \\
\hline Platelet count $\left(\mathrm{x} 10^{3} / \mathrm{mm}^{3}\right)$ & $345 \pm 52$ & $337 \pm 44$ & 0.523 \\
\hline GIT upset & $6(20.0)$ & $2(6.7)$ & 0.254 \\
\hline Rash & $8(26.7)$ & $3(10)$ & 0.095 \\
\hline
\end{tabular}

Data are expressed as mean \pm standard deviation, median (range), ratio and frequency (percentage).

\section{Discussion}

Thalassemia major is a growing health and economic problem in the Mediterranean region, with the modified guidelines for transfusion and iron chelation that improved survival of these patients. Iron overload and hemosiderosis are the major causes of morbidity and mortality, and therefore effective iron chelation remains the target of research that aims to reducie serum ferritin levels to between 500 and $1500 \mu \mathrm{g} / \mathrm{L}$, which matches transfusional iron loading and maintains acceptable hepatic and cardiac iron load with fewer side effects (17). We aimed at comparing the available iron chelators DFX and DFO regarding their efficacy for reducing serum ferritin and any adverse effects in a prospective, randomized study conducted at a single tertiary center accepting referrals from throughout Egypt. The patients who were included were randomized to treatment with either of the chelating agents studied after a washout period, and the baseline ferritin levels were comparable between the two groups $(p=$ 0.255). The mean reduction in serum ferritin and the number of patients reaching target levels below $1500 \mu \mathrm{g} / \mathrm{L}$ were not statistically different ( $\mathrm{p}=0.315$ and 0.598 , respectively). DFX has the advantage of oral administration with longer half-life that allows once-daily dosing, and it is generally well-tolerated. Its efficacy is dose dependent, the development of this chelator involved well-planned and vast clinical trials, leading to many studies that showed the effectiveness of DFX in decreasing ferritin and liver iron concentration (LIC) $(9,14,21-23)$. The development of adverse effects seems to be idiosyncratic and not dose dependent (22). Its most serious side effect is renal impairment that is indicated by a decrease in creatinine clearance to less than $40 \mathrm{ml} / \mathrm{min}$, albuminuria or an increase in serum creatinine above one third its baseline value or above the age-related upper reference values (9). Other common side effects are gastrointestinal disorders, skin rashes, and increase of hepatic transaminases $(9,14)$. Rare side effects include anaphylaxis, cytopenias, Fanconi type nephrotic syndrome, gastrointestinal ulceration and hemorrhage, impaired hearing, and ophthalmological problems (24). Taher et al. had presented reassuring safety data (22), also Pennell et al. in the large EPIC trial, demonstrated the efficacy of DFX in the improvement of myocardial iron (25). Regular administration of DFO has been shown to lower serum ferritin levels (9), to keep LIC at acceptable levels, to maintain heart function $(26,27)$, and to improve survival rates (28). Its adverse effects 
include local reactions that are managed by local anesthetics or topical steroids, growth delay, and bony abnormalities due to epiphyseal dysgenesis, impaired hearing and visual disturbances, and sepsis, such as Yersinia enterocolitis and Klebsiella infections $(20,29,30)$. Ophthalmologic and audiologic toxicities are more likely to occur when the DFO dose is high relative to the iron burden. The risk of these side effects can be minimized by maintaining the ratio of deferoxamine dose $(\mathrm{mg} / \mathrm{kg})$ to the serum ferritin level at less than $0.025(20)$. On studying the safety of both agents, our study did not record any serious adverse effects to either drugs, and no discontinuation occurred. Serum transaminases were significantly higher with DFO $(\mathrm{p}=0.022$ and 0.020 for ALT and AST, respectively). Blood urea was higher with DFX $(\mathrm{p}<0.001)$, however the levels were within the clinically-accepted range. Serum creatinine, absolute neutrophilic and platelet counts were comparable between the two groups $(\mathrm{p}=$ $0.148,0.434$, and 0.523 , respectively). Gastrointestinal upset and skin rash occurred more frequently with DFX ( $\mathrm{p}=$ 0.254 and 0.095 , respectively). Therefore, both drugs have comparable safety profiles, as the adverse effects noted did not reach clinical significance or lead to discontinuation of treatment with either agent. In the light of the comparable efficacy and safety of both agents for the reduction of iron overload, as was reported in the monotherapy of patients with transfusion-dependent thalassemia $(31,32)$, the oral preparation merits convenience and therefore patient compliance and adherence to treatment regimen that needs to be taken on a long-term basis.

\section{Conclusions}

With appropriate dosing and compliance with drugs, DFX and DFO are generally well tolerated, safe, and effective in reducing serum ferritin levels in iron-overloaded, regularly-transfused thalassemia major patients. The oral DFX is recommended due to more convenience to assure adherence to treatment regimen.

\section{Acknowledgments:}

The authors acknowledge all the staff members of the unit who were involved in the care of the patients.

\section{Conflict of Interest:}

There is no conflict of interest to be declared.

Authors' contributions:

Both authors contributed to this work and article equally. Both authors read and approved the final manuscript.

\section{References}

1) Shawky RM, Kamal TM. Thalassemia intermedia: An overview. Egyptian Journal of Medical Human Genetics. 2012; 13(3): 245-55. doi: 10.1016/j.ejmhg.2012.03.006.

2) El-Beshlawy A, Manz C, Naja M, Eltagui M, Tarabishi C, Youssry I, et al. Iron chelation in thalassemia: combined or monotherapy? The Egyptian experience. Ann Hematol. 2008; 87(7): 545-50. doi: 10.1007/s00277-008-0471-2. PMID: 18351337.

3) Aessopos A, Berdoukas V, Tsironi $\mathrm{M}$. The heart in transfusion dependent homozygous thalassemia todayprediction, prevention and management. Eur J Haematol. 2008; 80(2): 93-106. doi: 10.1111/j.16000609.2007.01018. PMCID: PMC2253710.

4) Crisponi G, Remelli M. Iron chelating agents for the treatment of iron overload. Coord Chem Rev. 2008; 252(10-11): 1225-40. doi: 10.1016/j.ccr.2007.12.014.

5) Gardenghi S, Marongiu MF, Ramos P, Guy E, Breda L, Chadburn A, et al. Ineffective erythropoiesis in beta-thalassemia is characterized by increased iron absorption mediated by down-regulation of hepcidin and up-regulation of ferroportin. Blood. 2007; 109(11): 5027-35. doi: 10.1182/blood-2006-09-048868. PMID: 17299088, PMCID: PMC1885515.

6) Ricchi P, Ammirabile M, Spasiano A, Costantini S, Cinque P, Di Matola T, et al. Combined chelation therapy in thalassemia major with deferiprone and desferrioxamine: a retrospective study. Eur J Haematol. 2010; 85(1): 36-42. doi: 10.1111/j.1600-0609.2010.01447. PMID: 20331740.

7) Berdoukas V, Farmaki K, Carson S, Wood J, Coates T. Treating thalassemia major-related iron overload: the role of deferiprone. J Blood Med. 2012; 3: 119-29. doi: 10.2147/JBM.S27400. PMID: 23112580, PMCID: PMC3480237.

8) Olivieri NF, Nathan DG, MacMillan JH, Wayne AS, Liu PP, McGee A, et al. Survival in Medically Treated Patients with Homozygous B-Thalassemia. N Engl J Med. 1994; 331(9): 574-8. doi: 10.1056/NEJM 199409013310903. PMID: 8047081. 
9) Cappellini MD, Cohen A, Piga A, Bejaoui M, Perrotta S, Agaoglu L, et al. A phase 3 study of deferasirox (ICL670), a once-daily oral iron chelator, in patients with beta-thalassemia. Blood. 2006; 107(9): 3455-62. doi: 10.1182/blood-2005-08-3430. PMID: 16352812.

10) Porter J, Galanello R, Saglio G, Neufeld EJ, Vichinsky E, Cappellini MD, et al. Relative response of patients with myelodysplastic syndromes and other transfusion-dependent anaemias to deferasirox (ICL670): a 1-yr prospective study. Eur J Haematol. 2008; 80(2): 168-76. doi: 10.1111/j.16000609.2007.00985. PMID: 18028431, PMCID: PMC2268958.

11) Jensen PD. Evaluation of iron overload. Br J Haematol. 2004; 124(6): 697-711. doi:10.1111/j.1365-2141. 2004.04838.

12) Kwiatkowski JL. Real-world use of iron chelators. Hematology Am Soc Hematol Educ Program. 2011; 2011: 451-8. doi: 10.1182/asheducation-2011.1.451. PMID: 22160073.

13) Hershko C. Pathogenesis and management of iron toxicity in thalassemia. Ann NY Acad Sci. 2010; 1202 : 1-9. doi: 10.1111/j.1749-6632.2010.05544. PMID: 20712765.

14) Cappellini MD, Porter J, El-Beshlawy A, Li C, Seymour JF, Elalfy M, et al. Tailoring iron chelation by iron intake and serum ferritin: the prospective EPIC study of deferasirox in 1744 patients with transfusiondependent anemias. Haematologica. 2010; 95(4): 557-66. doi: 10.3324/haematol.2009.014696. PMCID: PMC2857545.

15) Galanello R, Agus A, Campus S, Danjou F, Giardina PJ, Grady RW. Combined iron chelation therapy. Ann N Y Acad Sci. 2010; 1202: 79-86. doi: 10.1111/j.1749-6632.2010.05591. PMID: 20712777.

16) Saliba AN, Harb AR, Taher AT. Iron chelation therapy in transfusion-dependent thalassemia patients: current strategies and future directions. J Blood Med. 2015; 6: 197-209. doi: 10.2147/JBM.S72463. PMID: 26124688, PMCID: PMC4476479.

17) Ware HM, Kwiatkowski JL. Optimal Use of Iron Chelators in Pediatric Patients. Clin Adv Hematol Oncol. 2013; 11(7): 433-41.

18) Goldberg SL, Giardina PJ, Chirnomas D, Esposito J, Paley C, Vichinsky E. The palatability and tolerability of deferasirox taken with different beverages or foods. Pediatr Blood Cancer. 2013; 60(9): 1507-12. doi: 10.1002/pbc.24561. PMID: 23637051.

19) Porter JB. Practical management of iron overload. Br J Haematol. 2001; 115(2): $239-52$. doi: 10.1046/j.1365-2141.2001.03195. PMID: 11703317.

20) Porter JB, Jaswon MS, Huehns ER, East CA, Hazell JW. Desferrioxamine ototoxicity: evaluation of risk factors in thalassaemic patients and guidelines for safe dosage. Br J Haematol. 1989; 73(3): 403-9. doi: 10.1111/j.1365-2141.1989.tb07761. PMID: 2605127.

21) Taher A, El-Beshlawy A, Elalfy MS, Al Zir K, Daar S, Habr D, et al. Efficacy and safety of deferasirox, an oral iron chelator, in heavily iron-overloaded patients with beta-thalassaemia: the ESCALATOR study. Eur J Haematol. 2009; 82(6): 458-65. doi:10.1111/j.1600-0609.2009.01228. PMID: 19187278, PMCID: PMC2730551.

22) Taher A, Cappellini MD, Vichinsky E, Galanello R, Piga A, Lawniczek T, et al. Efficacy and safety of defera $\neg$ sirox doses of $>30 \mathrm{mg} / \mathrm{kg}$ per $\mathrm{d}$ in patients with transfusion-dependent anaemia and iron overload. Br J Haematol. 2009; 147(5): 752-9. doi: 10.1111/j.1365-2141.2009.07908. PMID: 19764988, PMCID: PMC2779992.

23) Cappellini MD, Taher A. Long-term experience with deferasirox (ICL670), a once-daily oral iron chelator, in the treatment of transfusional iron overload. Expert Opin Pharmacother. 2008; 9(13): 2391-402. doi: 10.1517/14656566.9.13.2391. PMID: 18710363.

24) Cappellini MD, Bejaoui M, Agaoglu L, Canatan D, Capra M, Cohen A, et al. Iron chelation with deferasirox in adult and pediatric patients with thalassemia major: efficacy and safety during 5 years' follow-up. Blood. 2011; 118(4): 884-93. doi: 10.1182/blood-2010-11-316646. PMID: 21628399.

25) Pennell DJ, Porter JB, Cappellini MD, El-Beshlawy A, Chan LL, Aydinok Y, et al. Efficacy of deferasirox in reducing and preventing cardiac iron overload in beta-thalassemia. Blood. 2010; 115(12): 2364-71. doi: 10.1182/blood-2009-04-217455. PMID: 19996412.

26) Freeman AP, Giles RW, Berdoukas VA, Talley PA, Murray IP. Sustained normalization of cardiac function by chelation therapy in thalassaemia major. Clin Lab Haematol. 1989; 11(4): 299-307. doi: 10.1111/j.13652257.1989.tb00227. PMID: 2605872.

27) Wolfe L, Olivieri N, Sallan D, Colan S, Rose V, Propper R, et al. Prevention of cardiac disease by subcutaneous deferoxamine in patients with thalassemia major. N Engl J Med. 1985; 312(25): 1600-3. doi: 10.1056/NEJM198506203122503. PMID: 4000198. 
28) Zurlo MG, De Stefano P, Borgna-Pignatti C, Di Palma A, Piga A, Melevendi C, et al. Survival and causes of death in thalassaemia major. Lancet. 1989; 2(8653): 27-30. doi: 10.1016/S0140-6736(89)90264. PMID: 2567801.

29) Chan GC, Chan S, Ho PL, Ha SY. Effects of chelators (deferoxamine, deferiprone and deferasirox) on the growth of Klebsiella pneumoniae and Aeromonas hydrophila isolated from transfusion-dependent thalassemia patients. Hemoglobin. 2009; 33(5): 352-60. doi: 10.3109/03630260903211888. PMID: 19814682.

30) Orzincolo C, Scutellari PN, Castaldi G. Growth plate injury of the long bones in treated beta-thalassemia. Skeletal Radiol. 1992; 21(1): 39-44. PMID: 1546335.

31) Lal A, Porter J, Sweeters N, Ng V, Evans P, Neumayr L, et al. Combined Chelation Therapy with Deferasirox and Deferoxamine in Thalassemia. Blood Cells Mol Dis. 2013; 50(2): 99-104. doi: 10.1016/j.bcmd.2012.10.006. PMID: 23151373, PMCID: PMC3592978.

32) Porter JB. Optimizing iron chelation strategies in beta-thalassaemia major. Blood Rev. 2009; 23(Suppl 1): S3-7. doi: 10.1016/S0268-960X(09)70003-7. PMID: 20116637. 